\title{
EVALUATION OF LIPID PROFILE IN YOUNG ADULT STROKE PATIENT AT M Y HOSPITAL INDORE, MADHYA PRADESH
}

\section{Dr Rajesh Turkar}

\section{Dr Ruchir Khare*}

\section{Dr Pratiksha Piplewar}

\author{
Associate Professor, Deptt. Of Orthopaedics, N S C B Medical College,
} Jabalpur.

Associate Professor, Deptt. Of Biochemistry, N S C B Medical College, Jabalpur. ${ }^{*}$ Corresponding Author

ABSTRACT Consultant Nephrologist, JHRC, Jabalpur. \begin{abstract}
perfusion of brain causing acute neurological deficit. Diabetes mellitus and dyslipidaemia, along with hypertension and smoking are the leading risk factors for the occurrence of stroke. It is most common in elderly patients, but stroke can occur at any age, including childhood. There are many risk factors found to be associated with the stroke but role of lipid abnormality as major risk factor is consistently observed. Aim \& Objectives: To evaluate lipid profile status in young patients suffering from stroke and its relationship with etiology of stroke. Material \& Methods: This prospective clinical study was conducted in M Y Hospital, Indore in the young (15-45 years) patients suffering from stroke attended the medicine department. The total50 patients were included in the study after informed consent. Complete lipid profile was evaluated using serum sample of patients by standard enzymatic methods in the central lab of hospital. Results \& Observations: Total cholesterol, Triglycerides, HDL, LDL were found abnormal in $28,16 \%, 82 \%, 62 \%$ subjects presented with stroke. Out of theses patients presented with abnormal lipid status the percentage of ischaemic stroke was $13 \%, 7 \%, 32 \%, 27 \%$ respectively and haemorrhagic stroke was observed in $01 \%, 01 \%, 09 \%, 04 \%$ respectively. Conclusions: Our study concluded that relation of dyslipidaemia with ischaemic and haemorrhagic stroke patients isn't consistent and more related to ischaemic stroke as compared to haemorrhagic stroke.
\end{abstract} Introduction: Stroke is classically characterized as a neurological deficit attributed to an acute focal
injury of the central nervous system due to impairment of cerebral circulation, resulting in abnormal

\section{KEYWORDS : Stroke, Dyslipidaemia, Ischaemic stroke, Haemorrhagic stroke}

\section{INTRODUCTION}

Stroke is classically characterized as a neurological deficit attributed to an acute focal injury of the central nervous system due to impairment of cerebral circulation, resulting in abnormal perfusion of brain causing acute neurological deficit. Blood supply may be impaired by cerebral infarction, intracerebral hemorrhage and subarachnoid hemorrhage. There are two types of stroke. First is an Ischemic stroke (87\%) which may occur due to obstruction of arteries by thrombus or embolus while hemorrhagic strokes are caused by rupture of artery.[1]

Stroke is a major cause of disability and third leading cause of death worldwide. According to the World Health Organization (WHO), stroke is the second leading cause of death for people above the age of 60 years, and the fifth leading cause in people aged 15 to 59 years old. [2] There are 15 million people worldwide who suffer a stroke each year. Each year, nearly six million people worldwide die from stroke. One in six people worldwide will have a stroke in their lifetime. Every six seconds, stroke kills some. Stroke claims more than twice as many lives as AIDS. [3]

In high income countries, the incidence of stroke is 217 per 100,000 person-years and the prevalence is 715 per 100,000 people, compared with low income countries where the incidence is 281 per 100,000 person-years and the prevalence is 393 per 100,000 people. [4]

Stroke rates in middle-aged people are five to ten times higher in Pakistan, India, Russia, China, and Brazil, compared with the United Kingdom or United States. South Asia is home to $20 \%$ of the world's population and has one of the highest burdens of cardiovascular disease in the world. [5]

It is more frequently found in third world countries. About $20 \%$ of the world's population lives in South Asia and stroke is 5-10 times more frequent in South Asia than USA and UK. Contrary to decline in the incidence of the disease in the Western population, the burden of the disease in South Asian countries (India, Pakistan, Bangladesh, and Sri Lanka) has inclined and is expected to rise ( 1 )

Intra cerebral haemorrhage is the most common type of intracranial haemorrhage. It accounts for $10 \%$ of all strokes and is associated with a $50 \%$ case fatality rate. Incidence rates are particularly high in Asians and blacks. [6]

The prevalence of stroke in India shows a huge variation of 147-922/100,000 across diverse community-based studies. According to the India stroke factsheet updated in 2012, the estimated age-adjusted prevalence rate for stroke ranges between $84 / 100,000$ and $262 / 100,000$ in rural and between $334 / 100,000$ and $424 / 100,000$ in urban areas. [7]

According to Madhya Pradesh: Disease Burden Profile, 1990 to 2016 stroke was ranked fifth among the fifteen leading cause for the most years of life lost and $8^{\text {th }}$ leading cause of DALYs in both sexes. In 1990 stroke was at thirteenth position which is now stepped up to $8^{\text {th }}$ position in terms of DALYs. [8]

Diabetes mellitus and dyslipidaemia, along with hypertension and smoking are the leading risk factors for the occurrence of stroke. It is most common in elderly patients, but stroke can occur at any age, including childhood. [9]

There are many risk factors found to be associated with the stroke but role of lipid abnormality as major risk factor is consistently observed in many studies. [1] [4] [6] [10] [11].

Various abnormalities in lipid profile have been reported in young patients with stroke. Both hypercholesterolemia and hypertriglyceridemia appear to be important risk factors for atherosclerosis. Low HDL cholesterol levels are commonly associated with other lipid and apolipoproteins abnormalities causing stroke.[12] 
The relationship between lipids and stroke is complex. In most epidemiological cohorts, there is a direct relationship between cholesterol levels and ischemic stroke. The relationship of lipids to ischemic stroke, however, varies by stroke subtype, with associations strongest for atherosclerotic subtypes. Conversely, there is an increased risk of intracerebral hemorrhage (ICH) at low cholesterol levels, and there is evidence that small vessel disease may share a similar profile of inverse association with lipid levels [13].

Looking at the ambiguity between lipid level and its relationship with the type of stroke, this study was carried out to evaluate the association between dyslipidaemia and stroke in patients who presented to M Y hospital, Indore, M.P.

AIM \& OBJECTIVES: To evaluate lipid profile status in young patients suffering from stroke and its relationship with etiology of stroke.

\section{MATERIAL \& METHODS}

This prospective clinical study was conducted in M Y Hospital, Indore in the young (15-45 years) patients suffering from stroke attended the medicine department. After complete physical and clinical examination and investigation reports, those patients who had fulfilled the inclusion and exclusion criteria were included in the study. The total50 patients were included in the study after informed consent. Patients of both type (ischaemic and haemorrhagic) were included in the study. Complete lipid profile was evaluated using serum sample of patients by standard enzymatic methods in the central lab of hospital. ATP III classification was followed for dyslipidaemia (Table 1) Patients with brain tumour, head injury, transient ischaemic attack, syncopal attacks and presumptive diagnosis of stroke with no evidence on CT were excluded from the study. Results were expressed in percentage, mean and standard deviation. Data were analyzed using Microsoft excel software with windows 7 platform.

\section{OBSERVATION \& RESULTS}

In our study only patients belonging to age group 18 to 45 were included. There were total 21 female and 29 males. Maximum number of female patients were age group of 21-25 while maximum male patients were age group of 36-40. Only one female and two males were of less than 20 years of age.

Table-1: ATP III guidelines

\begin{tabular}{|l|l|l|l|l|l|}
\hline LDLc & \multicolumn{2}{l|}{ Total cholesterol } & \multicolumn{2}{l|}{ HDLc } \\
\hline$<100$ & Optimal & $<200$ & Desirable & $<40$ & Low \\
\hline $100-129$ & Near optimal & $200-239$ & Borderline high & $\geq 60$ & High \\
\hline $130-159$ & Borderline high & $\geq 240$ & High & & \\
\hline $160-189$ & High & & & & \\
\hline$>190$ & Very High & & & & \\
\hline
\end{tabular}

Table-2: Lipid profile in all patients

\begin{tabular}{|l|l|l|}
\hline Parameter & Mean & Std.Dev. \\
\hline Cholesterol (mg\%) & 172.94 & 50.31 \\
\hline Triglycerides (mg\%) & 130.88 & 33.02 \\
\hline High Density Lipid (mg\%) & 35.52 & 8.08 \\
\hline Low Density Lipid (mg\%) & 115.568 & 42.89 \\
\hline
\end{tabular}

Table-3: Lipid profile associated with stroke

\begin{tabular}{|l|l|l|l|l|}
\hline Lipid (N=50) & Normal & Abnormal & $\begin{array}{l}\text { Normal } \\
(\%)\end{array}$ & $\begin{array}{l}\text { Abnormal } \\
(\%)\end{array}$ \\
\hline $\begin{array}{l}\text { Total cholesterol } \\
(<200)\end{array}$ & 36 & 14 & 72 & 28 \\
\hline Triglycerides $(<150)$ & 42 & 08 & 84 & 16 \\
\hline HDL (M $>40 ;$ F $>50)$ & 9 & 41 & 18 & 82 \\
\hline LDL $(<100)$ & 19 & 31 & 38 & 62 \\
\hline
\end{tabular}

Table-4: Lipid profile associated with type of Stroke

\begin{tabular}{|c|c|c|c|c|c|c|}
\hline \multirow{2}{*}{$\begin{array}{l}\text { Lipid } \\
(\mathrm{N}=50)\end{array}$} & \multirow[t]{2}{*}{ Normal } & \multicolumn{2}{|c|}{ Type of Stroke } & \multirow{2}{*}{\begin{tabular}{|c|} 
Abn- \\
ormal \\
\end{tabular}} & \multicolumn{2}{|c|}{ Type of Stroke } \\
\hline & & $\begin{array}{c}\text { Ischaemic } \\
(\mathrm{N}=39)\end{array}$ & $\begin{array}{l}\mathrm{ICH} \\
(\mathrm{N}= \\
11)\end{array}$ & & $\begin{array}{c}\text { Ischaemic } \\
\quad(\mathrm{N}=39)\end{array}$ & $\begin{array}{l}\mathrm{ICH} \\
(\mathrm{N}= \\
11)\end{array}$ \\
\hline \begin{tabular}{|l|} 
Total \\
cholesterol \\
$(<200)$ \\
\end{tabular} & 36 & 28 & 08 & 14 & 13 & 01 \\
\hline $\begin{array}{l}\text { Triglycerides } \\
(<150)\end{array}$ & 42 & 32 & 10 & 08 & 07 & 01 \\
\hline $\begin{array}{l}\text { HDL }(M>40 ; \\
F>50)\end{array}$ & 9 & 7 & 2 & 41 & 32 & 09 \\
\hline LDL $(<100)$ & 19 & 12 & 07 & 31 & 27 & 04 \\
\hline
\end{tabular}

\section{Types of stroke}

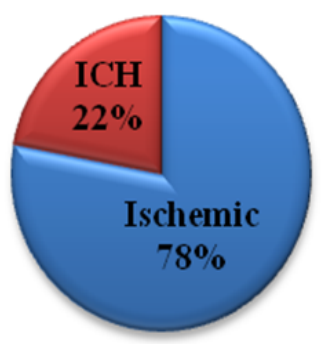

Fig.1 Percentage of types of stroke out of total patients

\section{DISCUSSION}

This study was conducted in young individuals of both sexes suffering from strokes for one year at M Y Hospital, Indore M. P. Patients suffering from both type of strokes (Ischaemic and haemorrhagic) were included in the study. Stroke is a very common pathological condition leading to morbidity and mortality at large scale. Contrary to decline in the incidence of the disease in the Western population, the burden of the disease in South Asian countries (India, Pakistan, Bangladesh, and Sri Lanka) has inclined and is expected to rise.

Conflicting reports have been published about the significance of hyperlipidemia in the development of cerebrovascular disease. Some investigators, who have examined survivors of attacks of ischemic cerebrovascular disease, have observed elevated mean concentrations of serum cholesterol and/or triglyceride [14]

In our study most of the patients were between 19 to 45 years of age group. Maximum number of female patients were age group of 21-25 while maximum male patients were age group of $36-40$ years. Only one female and two males were of less than 20 years of age.

A study conducted by Albuther J F et al [12] in 94 patient suffering from Ischaemic stroke, patients were from age 15 to 45 years. Out of 94 patients, 55 were males while 39 were females with mean age $35.8 \pm 8.2$ years). In another study by Nirmala A C et al [15] the youngest patient in the study was 18 years and the eldest was 44 years old. Maximum number of patients $(53.33 \%$ ) was more than 37 years age and less than 45 yrs group. Mean age with standard deviation was $35.23 \pm$ 7.37.

In our study total cholesterol were normal in 36 patients while abnormal in 14 patients. In 36 patients having normal total cholesterol level 28 were having ischaemic stroke while 8 were having hemorrhagic stroke. Out of 14 patients having abnormal total cholesterol 13 were having ischaemic etiology while only one were having hemorrhagic etiology. In our study 
36 patients were having cholesterol level less than $200 \mathrm{mg} \%$ while 14 patients were having cholesterol level more than 200 $\mathrm{mg} \%$. A study by Weir C J et al [16] concluded that serum cholesterol level is not a independent predictor for outcomes after stroke.

In our study triglycerides level were normal in 42 patients while abnormal in 08 patients. In 42 patients having normal triglycerides level 32 were having ischaemic stroke while 10 were having hemorrhagic stroke. Out of 08 patients having abnormal total cholesterol 07 were having ischaemic etiology while only one were having hemorrhagic etiology. In our study 42 patients were having triglycerides level less than $150 \mathrm{mg} \%$ while 08 patients were having cholesterol level more than 150 $\mathrm{mg} \%$.

In our study HDL level were normal in 09 patients while abnormal in 4 lpatients. In 09 patients having normal HDL level 07 were having ischaemic stroke while 02 were having hemorrhagic stroke. Out of 4 lpatients having abnormal HDL 32 were having ischaemic etiology while 09 were having hemorrhagic etiology. In our study 09 patients were having HDL level more than 40 while 41 patients were having HDL level less than 40 .

In our study LDL level were normal in 19 patients while abnormal in 3lpatients. In 19 patients having normal LDL level 12 were having ischaemic stroke while 07 were having hemorrhagic stroke. Out of 3 lpatients having abnormal LDL, 27 were having ischaemic etiology while 04 were having hemorrhagic etiology. In our study 19 patients were having LDL level less than $100 \mathrm{mg} \%$ while 31 patients were having LDL level more than $100 \mathrm{mg} \%$. Another study conducted by Das $\mathrm{P}$ et al in 36 stroke patients of 27-49 years of age concluded that dyslipidemia was significantly associated with stroke. [17] Similarly a study by Synthia A et al (11) concluded that there was a significant association of $56 \%$ between dyslipidaemia and stroke while a study by Siddeshwari et al [6] concluded that dyslipidaemia were present only in $14 \%$ patients but all the patients were more than 40 years of age while we have conducted this study in young adults (18-45 years). In one study conducted in Northern India by Rai O N [18] concluded that abnormal lipid values were found in 54 patients (Total 100). Total cholesterol was abnormal in $83 \%$ of ischemic stroke and $17 \%$ of hemorrhagic stroke. LDL cholesterol was abnormal in $86 \%$ of ischemic stroke and $14 \%$ of hemorrhagic stroke. Similar findings were observed in our study where 13 out of 14 patients having abnormal total cholesterol were having ischaemic stroke and 27 patients out of 31 having abnormal LDL cholesterol have suffered from ischaemic stroke.

In this study frequency of ischemic stroke patient was $78 \%$ while of hemorrhagic stroke was $22 \%$ which is comparable with a study by Khan S N et al [19] who also noted that $70.1 \%$ patients suffered from Ischemic stroke \& $29.9 \%$ from hemorrhagic stroke. In our study it was observed that total cholesterol and triglycerides level were normal in $72 \%$ and $84 \%$ patients respectively.

Our study showed a high occurrence of dyslipidaemia in the form of elevated LDL and decreased HDL. Mehndiratta MM et al [2] showed abnormal cholesterol and triglycerides levels as a risk factor.

\section{CONCLUSIONS}

Our study concluded that relation of dyslipidaemia with ischaemic and haemorrhagic stroke patients isn't consistent and more related to ischaemic stroke as compared to haemorrhagic stroke. in Adult Stroke Patient at Liaquat University Hospital Jamshoro, Sindh Liaquat Uni Med Health Sci 2016; Vol 15: (03):131-35

2. Findings from the Global Burden of Disease Study 2017 Lance

3. Gund B M, Jagtap P N , Ingale V B, Patil R Y Stroke: A Brain Attack IOSR Journal Of Pharmacy 2013; Volume 3 (8): 01-23

4. Da Lu, Pan Li, Yuying Zhou, Xiaolin Xu, Huihong Zhang, Liping Liu and Zhiyan Tian Association between serum non-highdensity lipoprotein cholesterol and cognitive impairment in patients with acute ischemic stroke BMC Neurology 2016; 16:154

5. Hashmi M, Khan M, Wasay M Growing Burden of Stroke in Pakistan: A Review of Progress and Limitations Int J Stroke 2013; Vol8(7): 575-581

6. Siddeswari R, Sudarsi B, Abhilash T, Rao N S A study on risk factors and lipid profile pattern in patients of stroke in Osmania General Hospital, Hyderabad, India International Journal of Research in Medical Sciences 2015; Vol 3(1):3337-3341

7. Jeyaraj Durai Pandian,a Paulin Sudhanb Stroke Epidemiology and Stroke Care Services in India Journal of Stroke 2013;15(3):128-134

8. Madhya Pradesh: Disease Burden Profile, 1990 to $2016 \mathrm{http} / / / \mathrm{www}$. healthdata.org/sites/default/files/files/Madhya_Pradesh - Disease Burden Profile\%5B1\%5D.pdf (assessed on 05.04.2019)

9. V Vranic J D, Alajbegovic A, Asimi V Z, Niksic M, Campara M T, Salcic S, Celo A Predilection Role Diabetes Mellitus and Dyslipidemia in the Onset of Ischemic Stroke Med Arh. 2013; 67(2): 120-123

10. Cynthia A, Yogeesha KS Arunachalam R Dyslipidemia in stroke IOSR Journal of Dental and Medical Sciences 2014 Voll3(4) : 45-49

11. Tziomalos, Konstantinos, Athyros, Vasilios G., Karagiannis, Asterios, Mikhailidis, Dimitri P. Dyslipidemia as a Risk Factor for Ischemic Stroke Current Topics in Medicinal Chemistry,2009 Vol9(14):1291-1297

12. Albucher J F Ferrieres J, Ruidavets I B, Chaumeil B G,Perret B P Chollet F Serum lipids in young patients with ischaemic stroke: a case-control study Neurol Neurosurg Psychiatry 2000;69:29-33

13. Shadi Yaghi S, Elkind M S V, Lipids and Cerebrovascular Disease Research and Practice Stroke. 2015; 46:3322-3328

14. Murai A, Tanaka T, Miyahara T, Kameyama MLipoprotein Abnormalities in the Pathogenesis of Cerebral Infarction and Transient Ischemic Attack Stroke,1981; Vol 12(2):167-172

15. Nirmala A C, Mamatha TN, Priya Shree R, Avinash B H Study of Lipid Profile in Non Diabetic Stroke in Young Sch. J. App. Med. Sci., 2015; 3(3C):1259-1265

16. Weir C.J., Sattar N. Walters M.R, Lees K.R , Low Triglyceride, Not Low Cholesterol Concentration, Independently Predicts Poor Outcome following Acute Stroke Cerebrovasc Dis 2003;16:76-82

17. Das P, Bandyopadhyay M, Paul R, Singh R Study of underlying risk factors for stroke in young. Biomedical Research 2010; 21 (3): 272-276

18. Rai O N, Kumar A Study of serum lipid profile in stroke patients in Northern India Int J Adv Med. 2017:4(5):1374-1377

19. Salma N. Khanl, Ejaz Ahmed Vohra2 Risk factors for stroke:A hospital based study Pak J Med Sci 2007; Vol. 23(1): 17-22

\section{REFERENCES}

